\title{
Resilience Among Police Officers: a Critical Systematic Review of Used Concepts, Measures, and Predictive Values of Resilience
}

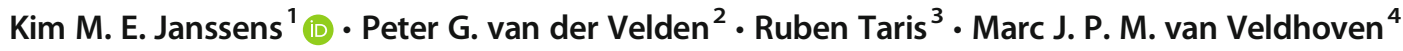

Published online: 6 November 2018

(C) The Author(s) 2018

\begin{abstract}
Resilience, hardiness, and psychological capital are considered to be important capacities for police officers to cope with and adapt to challenging stressful and potentially traumatic situations. Despite their growing popularity, a systematic review assessing used concepts and instruments for these capacities and synthesizing the results of studies on the predictive values of resilience, hardiness, and psychological capital among police officers is absent. The aim of the present study is to fill this gap of scientific knowledge, and for this purpose, a systematic literature search was conducted using PsycInfo, Pubmed, and Web of Science. We identified 17 cross-sectional and 5 longitudinal studies. Results showed that resilience, hardiness, and psychological capital were studied mostly in relation to physical and mental health variables. No study focused on officers' professional functioning. In both cross-sectional and longitudinal studies, associations with health variables were very weak to moderate, while cross-sectional studies mostly yielded stronger associations than longitudinal associations. In sum, we found no empirical support for the growing popularity.
\end{abstract}

Keywords PTSD $\cdot$ Resilience $\cdot$ Hardiness $\cdot$ Psychological capital $\cdot$ Police officers

\section{Introduction}

In the past decades resilience, hardiness, and psychological capital have gained growing attention and popularity (Aburn et al. 2016; Britt et al. 2016; Fletcher and Sarkar 2013; GarciaDia et al. 2013; Herrman et al. 2011; Windle 2011). They are considered to be important capacities for high-risk professions and especially police officers to cope with and adapt to challenging situations caused by operational or potentially traumatic stressors (McCanlies et al. 2014), organizational stressors (van der Velden et al. 2010), and work-private life conflicts (Paton et al. 2008). These stressors may put police

Kim M. E. Janssens

k.m.e.janssens@ tilburguniversity.edu

1 TRANZO, Scientific Center for Care and Welfare, Tilburg School of Social and Behavioral Sciences, Tilburg University, Warandelaan 2, 5037 AB Tilburg, The Netherlands

2 CentERdata, Tilburg University's Network on Health and Labor (NETHLAB), Tilburg, The Netherlands

3 Recruitment \& Selection Department, The National Police, The Hague, The Netherlands

4 Department of Human Resource Studies, Tilburg University, Tilburg, The Netherlands officers at risk for mental health problems such as anxiety and depression, sleep problems, PTSD, sickness leave, suicidal thoughts and suicide, and substance abuse (Berger et al. 2012; Lindsay 2008; Stanley et al. 2016; Slaven et al. 2011; Taloyan et al. 2016) that may negatively impact their functioning as officers, such as reduced performance and productivity (Fox et al. 2012; Levy-Gigi et al. 2016).

Importantly, the three concepts resilience, hardiness, and psychological do share several characteristics. Central themes that occur in various definitions of resilience are coping with adversity and trauma (Fletcher and Sarkar 2013; Johnston et al. 2015; Pangallo et al. 2015), positive adaptation (Aburn et al. 2016; Fletcher and Sarkar 2013; Johnston et al. 2015; Pangallo et al. 2015), and resilience being a dynamic process (Aburn et al. 2016; Johnston et al. 2015): resilience is defined as both a predictor and process variable (Cf. Britt et al. 2016; Hu et al. 2015; Olsson et al. 2003; Windle 2011). Others consider resilience as an outcome, such as the absence of PTSD symptoms (e.g., Bowler et al. 2012). More in general, it is viewed as the capacity to "bounce back" after adversity, but also to develop their capacity to deal with future events (Paton et al. 2008).

Like resilience, hardiness is considered to influence an individuals' interaction with others and coping with problems (Atella 1999) as described by the three facets of hardiness, e.g., commitment (approaching situations as meaningful and 
interesting), control (seeing stressors as changeable), and challenge (seeing change as an opportunity for growth and as a normal aspect of life rather than as threat; Kobasa 1979; Maddi and Kobasa 1984). Like resilience, hardiness is seen as a psychological skill for police officers that gives positive outcomes after experiencing stress and trauma (Andrew et al. 2008; Andrew et al. 2013; James et al. 2006).

Psychological capital (Luthans and Youssef-Morgan 2017; Luthans et al. 2007) consists of four facets: self-efficacy, optimism, hope, and finally resilience (i.e., when beset by problems and adversity, sustaining and bouncing back and even beyond to attain success; Luthans et al. 2007). The meta-analysis of Avey et al. (2011) showed that psychological capital predicted job satisfaction, organizational commitment, and psychological well-being (Cf. Farr-Wharton et al. 2016; Farr-Wharton et al. 2016; Ojedokun and Balogun 2015; Siu et al. 2015).

Despite the growing attention and popularity, to date, no systematic review has been conducted to assess and compare used concepts of resilience, hardiness, and psychological capital, used measures of and to synthesize the results of empirical studies among police officers.

\section{Aim of the Present Study}

The aim of the present systematic review is to fill this gap of scientific knowledge. In sum, the two main research questions of the present study are the following:

1. What concepts and measures of resilience are used in studies among police officers that focus the relationships between resilience, hardiness, and psychological capital on the one hand and officers' functioning or problems in functioning on the other?

2. To what extent does resilience predict officers' functioning or problems in functioning?

\section{Method}

A broad literature search was conducted using the electronic databases of PsycInfo, Pubmed, and Web of Science, with the following keywords and algorithm: for resilience (resilien* or hardiness or psychological capital) and for police officers (police or officer* or law enfor*). The asterisk (*) broadens a keyword by finding words that start with the same letters. We focused on journal articles in peer-reviewed academic journals published in English. Dissertations and "gray literature" were excluded. In advance, no exclusion keywords and algorithms were used to be able to identify as many relevant papers as possible. The search was not restricted to a particular publication date in the past. The search and coding of identified studies was conducted by the first author in collaboration with the second author. This systematic review was conducted and reported according to the PRISMA guideline (Cf. Moher et al. 2009), except that it was not registered in advance.

\section{Results}

\section{Identified and Selected Studies}

The primary search resulted in 828 hits (PsycInfo $=302$, Pubmed $=242$, Web of Science $=284$ ). Next, relevant articles were selected according to their titles and abstracts. After this selection, 162 articles remained $($ PsycInfo $=68$, Pubmed $=52$, Web of Science $=42$ ). A further selection was made based on the content of the full text. This gave a total of 51 potentially relevant articles published until February 2017. Of 51 studies, we finally only selected empirical cross-sectional and longitudinal studies, and selected studies that treated resilience (or described related terms) as a predictor in these analyses, resulting a final set of 22 articles. At this stage, we excluded literature reviews (e.g., Honig and Sultan 2006; Shochet et al. 2011), studies evaluating interventions aimed at enhancing resilience (e.g., Andersen et al. 2016; Ramey et al. 2016), and studies assuming that not having PTSD symptoms is being resilient (e.g., Bowler et al. 2012; Galatzer-Levy et al. 2011) because these studies do not focus on investigating the relationships between resilience and officers' functioning or problems in functioning (see Fig. 1).

\section{General Study Characteristics}

Table 1 provides a description of each study included in this review, e.g., authors; year of publication; sampling and design including response, demographics of respondents, the independent, and dependent measures; and the main results and conclusions. The main results and conclusions discuss the significant bivariate and multivariate associations.

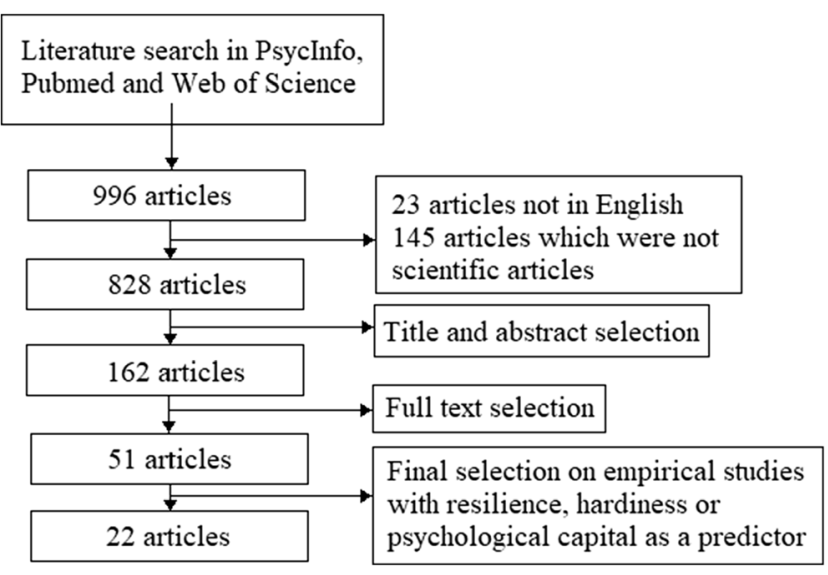

Fig. 1 Systematic literature search and selection process 


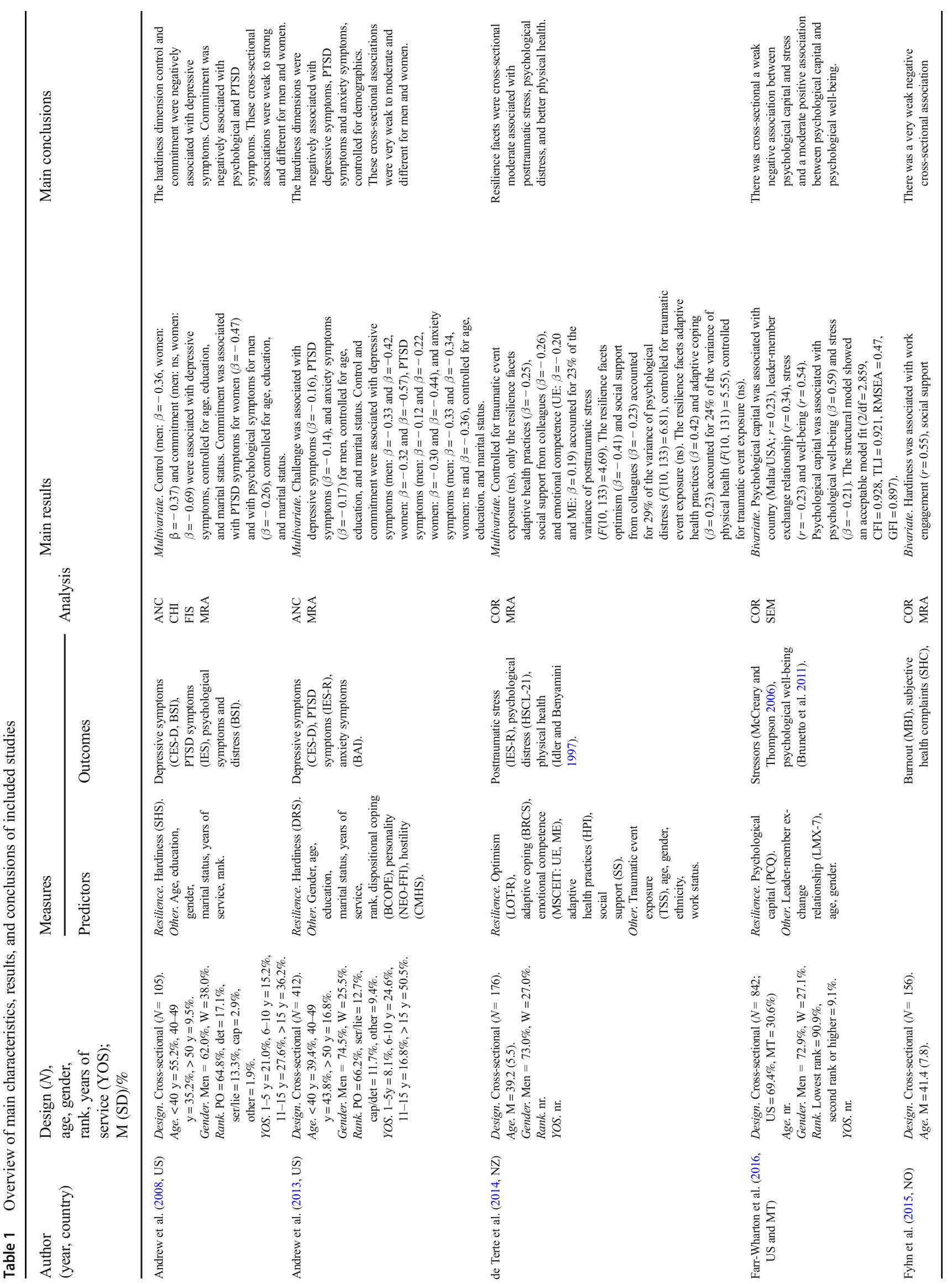




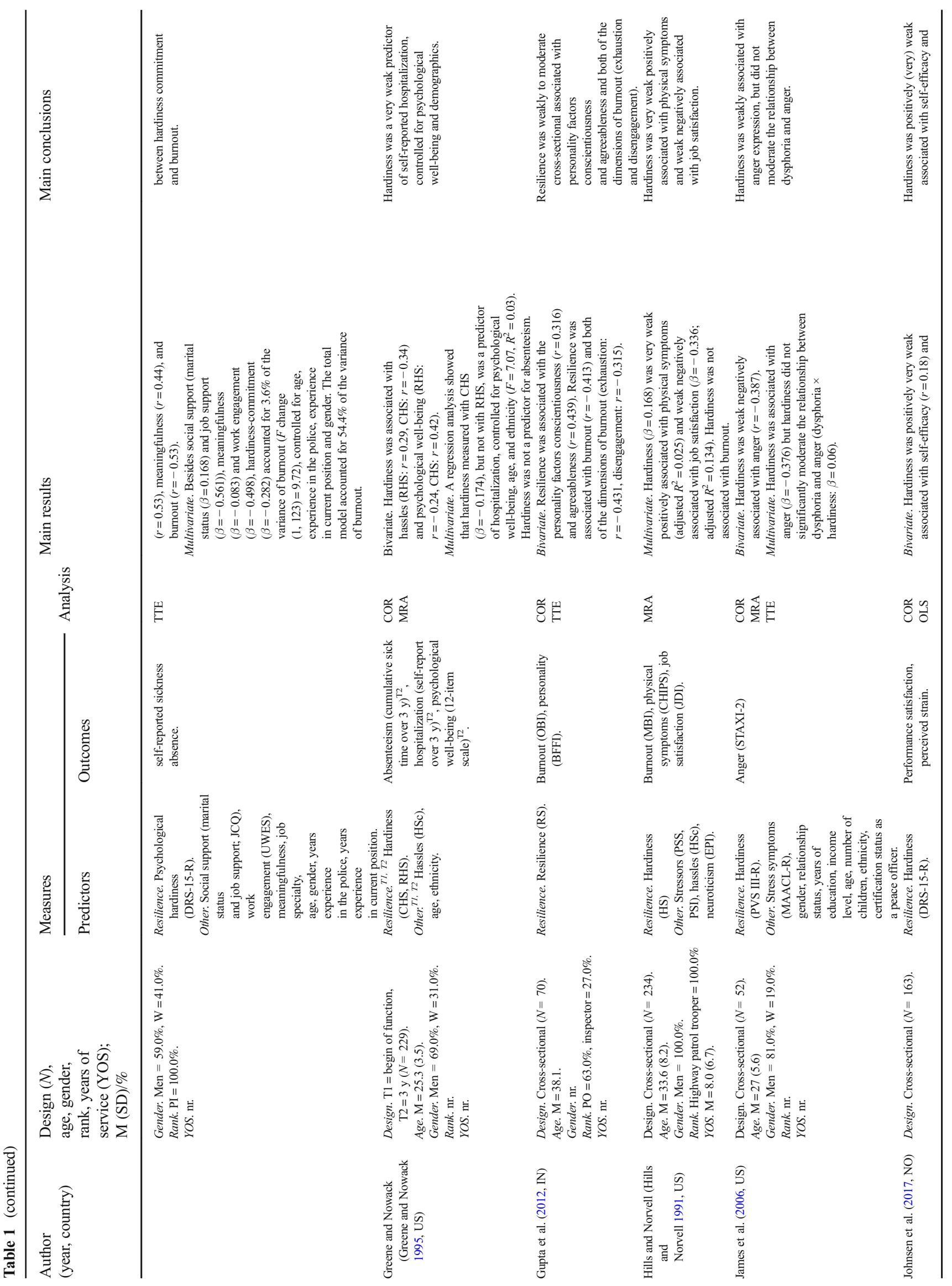




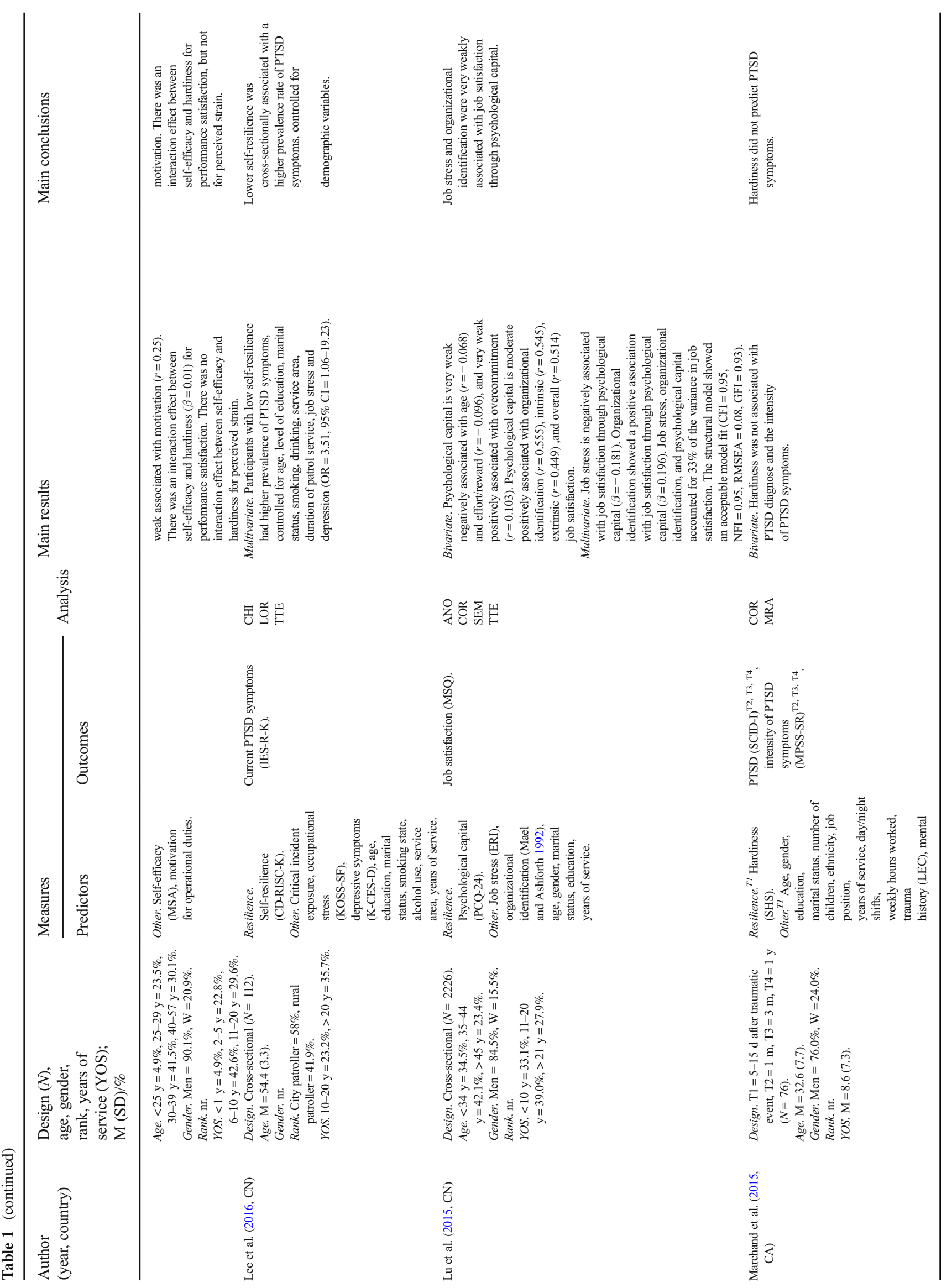




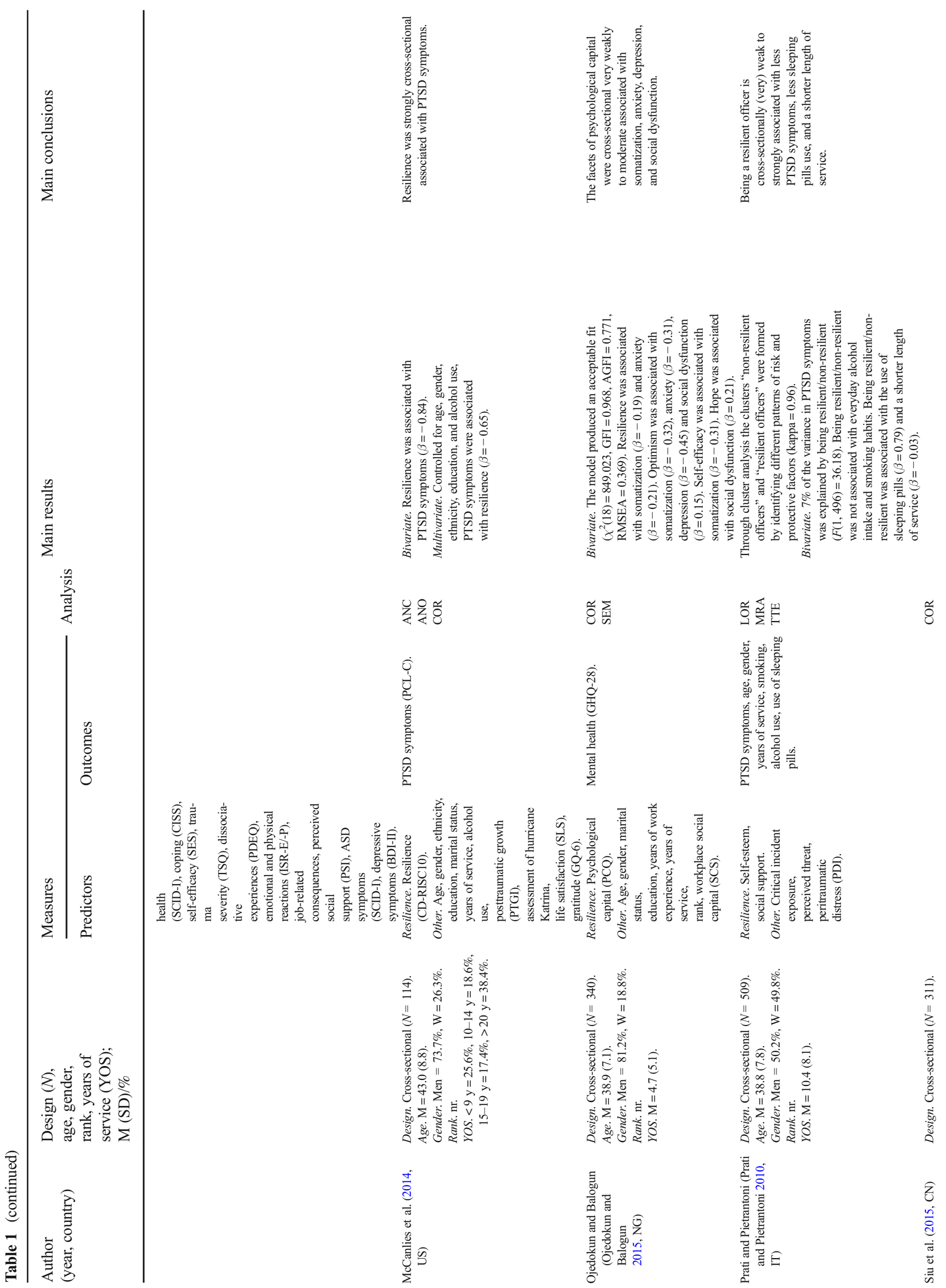




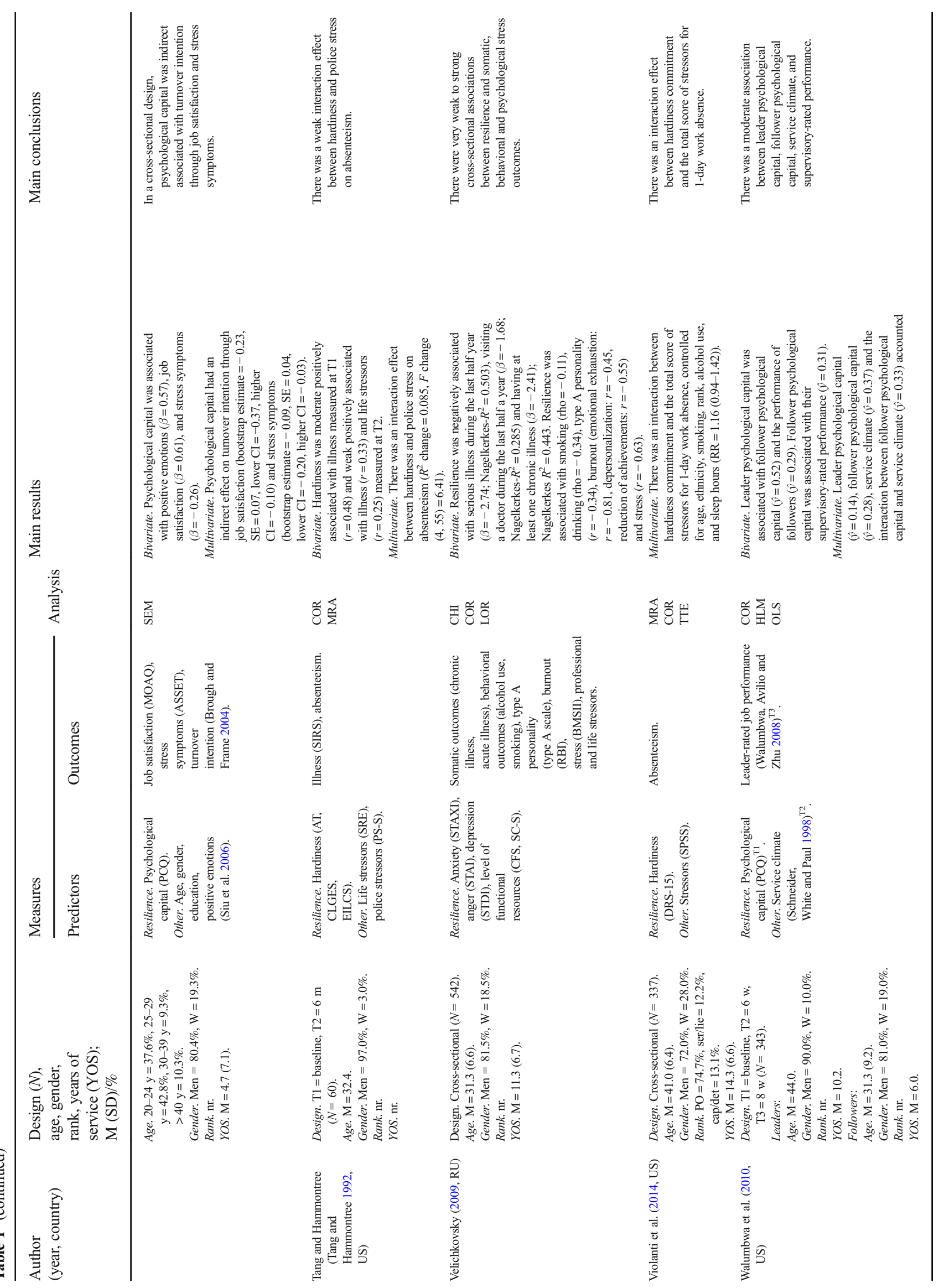




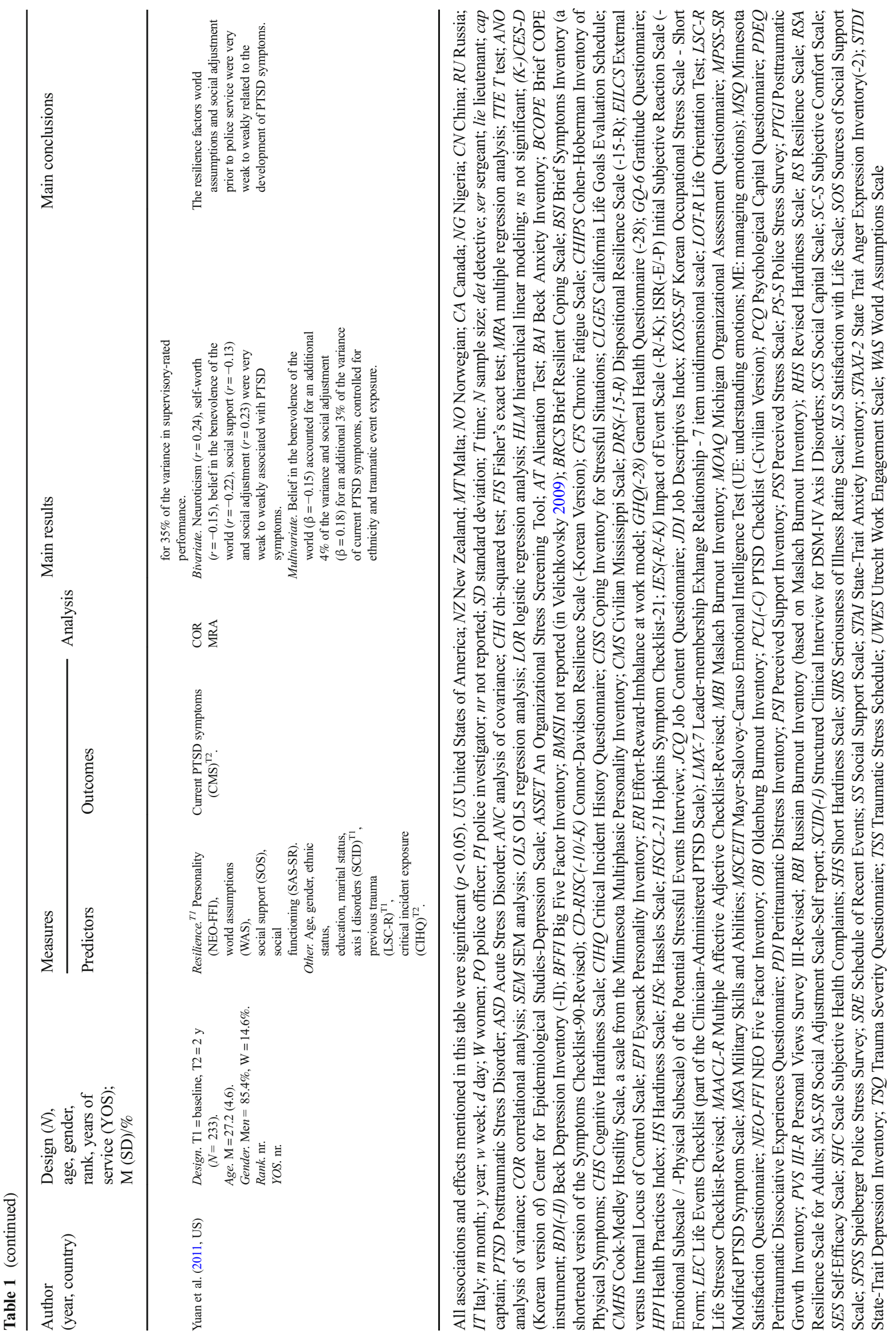


Most of the included studies were published since 2006, with a small majority of the studies published in recent years (2013-2017: $N=12,55 \%)$. The large majority $(N=17,77 \%)$ had a cross-sectional design. Five studies (Greene and Nowack 1995; Marchand et al. 2015; Tang and Hammontree 1992; Walumbwa et al. 2010; Yuan et al. 2011) had a longitudinal design with a minimum of 8 weeks and a maximum of 3 years between the baseline and final follow-up. The crosssectional studies had larger sample sizes (between $N=52$ and $N=2226$ ) than the longitudinal studies (between $N=60$ and $N=343)$. Most of the studies $(N=18)$ relied only on selfreport measurements. The studies of Marchand et al. (2015) and Yuan et al. (2011) conducted clinical interviews (SCID), combined with self-reported measures. Greene and Nowack (1995) and Violanti et al. (2014) used absenteeism data out of electronic databases. About 50\% $(N=11)$ was conducted in the USA. In all studies, more men than women participated, which corresponds with the male-female ratio among police officers. The mean age of the samples varied between 25.3 and 54.4 years. The mean years of service varied between 4.7 and 20.1 years. All studies focused on (general) police officers in patrol assignment besides the study of Fyhn et al. (2015), which focused on police investigators.

\section{Concepts and Instruments Capturing Resilience}

Table 2 provides an overview of the definitions used for resilience, hardiness, and psychological capital in each of the included studies. It includes some more or less standard definitions available in the wider literature, as well as some definitions created by the authors itself and conceptualizations of the definitions. Of the identified papers, eight studies (36\%) used the term resilience, nine studies (41\%) used the term hardiness, and five studies (23\%) used the term psychological capital.

The term resilience was considered as a uniform, unidimensional concept $(N=4)$ and as a combined multidimensional concept, consisting of several partial facets $(N=4)$. Although studies using the term resilience do differ in wordings of definitions, they all refer to resilience as an ability to deal with stressful situations.

Furthermore, Table 1 shows that resilience was measured in quite different ways, e.g., resilience was assessed by different instruments covering different topics. For example, de Terte et al. (2014) mentioned resilience as a combination of optimism, adaptive coping, emotional competence, adaptive health practices, and social support, and measured these concepts respectively with the Life Orientation Test, Brief Resilient Coping Scale, Mayer-Salovey-Caruso Emotional Intelligence Test, Health Practices Index, and Social Support Scale.

Hardiness, consisting of the facets of challenge, control, and commitment, was considered to be a personality state, trait, or style in the identified studies. Hardiness was most often measured with scales designed by Bartone: for example, the Short Hardiness Scale (SHS; Bartone 1995) or the Dispositional Resilience Scale-15 (DRS-15; Bartone 2007). These measures are both based on the longer Dispositional Resilience Scale (Bartone 2007).

Five studies measured psychological capital, e.g., a combination of resilience, self-efficacy, optimism, and hope (FarrWharton et al. 2016; Lu et al. 2015; Ojedokun and Balogun 2015; Siu et al. 2015; Walumbwa et al. 2010). All of these studies used the Psychological Capital Questionnaire to measure psychological capital, indicating that psychological capital was defined and assessed in a (much) more uniform way than resilience and hardiness.

All definitions in some way refer to abilities, strengths, styles, or traits enabling police officers to cope successfully with difficult, stressful, or adverse events (either as a moderator or mediator), thus enabling police officers to (keep) carry(ing) out their duties. However, none of the instruments assessed concrete behaviors showing that resilient police officers were indeed able to cope with adversity and stressful situations more successfully, e.g., to perform better in their law enforcement and related policing tasks.

\section{Measurements of Other Variables}

In the included studies, (mental) health problems were treated mostly as dependent variables, such as PTSD symptoms (e.g., Andrew et al. 2008; Andrew et al. 2013)), psychological distress (e.g., Andrew et al. 2008; de Terte et al. 2014), physical health (e.g., de Terte et al. 2014; Fyhn et al. 2015; Greene and Nowack 1995), and burnout (e.g., Fyhn et al. 2015; Gupta et al. 2012). There was much less attention for the relationship between resilience and non-health variables, like stressors (Farr-Wharton et al. 2016; Velichkovsky 2009), personality (Gupta et al. 2012; Velichkovsky 2009), and job-related variables (e.g., Hills and Norvell 1991; see Table 1).

Table 1 furthermore shows that the identified studies vary widely in terms of the measures used. For example, PTSD symptoms were measured with the Impact of Event Scale($\mathrm{R},-\mathrm{K})$, Structured Clinical Interview for DSM-IV Axis I Disorders, Modified PTSD Symptom Scale, PTSD checklist, and Civilian Mississippi Scale.

\section{Results Predictive Value of Resilience}

As shown in Table 1, dependent variables studied in relationship to resilience were predominantly (mental) health related.

\section{For Physical Health}

Five studies examined the predictive value of resilience for physical health of police officers. Greene and Nowack (1995) found in a longitudinal study of 3 years that hardiness was very weakly and negatively associated with 
Table 2 Overview of definitions and conceptualizations of resilience, hardiness, and psychological capital

Author (year, page number)

Andrew et al. (2008, p. 138)

Andrew et al. (2013)

de Terte et al. (2014, p. 416)

Farr-Wharton et al. (2016, p. 334)

Fyhn et al. (2015, p. 2)

Greene and Nowack

(Greene and Nowack 1995, p. 448)

Gupta et al. (2012, p. 2)

Hills and Norvell

(Hills and Norvell 1991, p. 31)

James et al. (2006, p. 38)

Johnsen et al. (2017, p. 2)

Lee et al. $(2016$, p. 1)

Lu et al. $(2015$, p. 15089)
Definition

'Resiliency is often used to imply an ability to 'bounce back.' Being able to bounce back is an important capability in situations that are difficult and stressful. (...) Hardiness refers to a personality trait that indicates the manner in which a person might interpret a critical incident, life stress, or traumatic event. Hardiness is thought to consist of three sets of cognitive style (Maddi, 1990)."

Not presented/clarified.

"Psychological resilience has been defined as the ability of an individual to rebound or recover from adversity (Leipold \& Greve, 2009) or as the ability to maintain psychological and physical health despite exposure to a traumatic event (Bonanno, 2004). Bonanno (2004) has further argued that psychological resilience is multidimensional because various factors have been found to protect individuals when faced with traumatic events."

"[Psychological capital] is a psychological emotional resource that humans have in varying quantities, and those with high [psychological capital] have a natural defence against stress and an internal mechanism for promoting positive employee outcomes, such as high psychological wellbeing and work engagement (Avey et al. 2011)."

"Hardiness is a personality style that influences the individual to cope with challenges in a constructive and proactive manner (Kobasa et al. 1982)." and "The hardiness measure consists of three factors: Commitment, control, and challenge (Kobasa 1979). Individuals high in these three domains generally seem to function and perform under difficult or even extreme conditions, by believing they can influence their situation, and positively reframe challenges they face (Kobasa et al. 1982)."

"Personality hardiness is typically conceptualized as a multidimensional construct consisting of internal locus of control (versus powerlessness), commitment to work and life activities (versus alienation), and perception of life changes and demands as a challenge (versus threat). Results from a growing body of studies suggest that personality hardiness may exert a protective effect against physical illness and psychological distress in the face of work and life stressors (Ganellen and Blaney 1984, Kobasa et al. 1982b, Kobasa et al. 1983, Kobasa and Puccetti 1983, Pierce and Molloy 1990, Hills and Norvell 1991, Wiebe and McCallum 1986)."

"Resilient employees 'bounce back' from circumstances that involve risk (Tusaie \& Dyer, 2004; Youssef \& Luthans, 2007). According to Wagnild and Young (1993) resilience moderates the negative effects of stress, and promotes adjustment to circumstances. Higher levels of resilience make the individual less vulnerable to burnout."

"Hardiness, a composite of the experience of control, challenge, and commitment, has been found to have a buffering effect on physical illness. ${ }^{4-6 "}$

"Kobasa (1979) originally defined hardiness in her work with Illinois Bell Telephone executives in the late 1970s. Kobasa found that executives undergoing major organizational stress could be characterized in two opposing ways. One group was vulnerable to health problems, performance problems, and attrition while another group tended to thrive in spite of the stressful circumstances experienced at work. Kobasa (1979) hypothesized that there were three inter-related personality characteristics (control, commitment, challenge) that predicted the differences between the two groups. Kobasa coined the term stress hardiness to describe the characteristics of the group that seemed to thrive under stress."

"Hardiness is a personality or cognitive style marked by increased levels of control, commitment, and challenge (Kobasa 1979; Maddi and Kobasa 1984)."

"The term self-resiliency was first used by Rutter in 1985 after he discovered that some people easily adapt to environmental difficulties and stressful situations, and has been used since. While resilient people can easily adapt to stressful situations, non-resilient people become impulsive and threatening; they overly control their demands and impulses, feel anxiety, and show signs of non-adaptability."

"Psychological capital (PsyCap) is positive state-like psychological capacities, and focuses on people's strength and how they grow and thrive. With the development of positive psychology, PsyCap has become an important internal resource for 
Table 2 (continued)

Author (year, page number)

Marchand et al. (2015)

McCanlies et al. (2014, p. 406)

Ojedokun and Balogun

(Ojedokun and Balogun 2015, p. 2)

Prati and Pietrantoni

(Prati and Pietrantoni 2010, p. 28)

Siu et al. (2015, p. 368)

Tang and Hammontree

(Tang and Hammontree 1992, p. 494)

Velichkovsky (2009, p. 540)

Violanti et al. (2014, p. 2)

Walumbwa et al. (2010, p. 938)
Definition

positive work behaviors, job attitudes (e.g., job satisfaction) and employee performance $[23,24] . "$

Not presented/clarified.

"Resilience has a number of different definitions, including the absence of psychopathology in children raised in abusive and neglectful environments, recovery of physical health following an injury or serious illness, and the ability to overcome stress and adversity while maintaining normal physical and psychological function (Agaibi and Wilson 2005; Wu et al., 2013).”

"According to Luthans et al. (2007), [psychological capital] is considered a positive psychological state characterized by confidence to take on and put in the needed effort to succeed at challenging tasks; making a positive attribution about succeeding now and in the future; persevering towards goals and, when required, redirecting paths to goals in order to succeed, and when beset by problems with adversity, sustaining and bouncing back and even beyond to attain success."

"Thus, the absence of negative change in behavioral outcomes could be considered an indicator of resilience, among many others."

"[Psychological capital] is positive state-like psychological capacities, its focus is on people's strength and how they grow and thrive. It has been defined as an individual's characteristics by (1) having confidence (self-efficacy) to take on and put in the necessary effort to succeed at challenging tasks; (2) making a positive attribution (optimism) about succeeding now and in the future; (3) persevering towards goals, and when necessary, redirecting paths to goals (hope) in order to succeed; and (4) when beset by problems and adversity, sustaining and bouncing back and even beyond (resiliency) to attain success (Luthans et al. 2007, p. 3)."

"Kobasa (1979) proposed hardiness as a resistance resource. The three crucial dimensions for hardiness are commitment, control, and challenge. For hardy individuals, the stresses or life events are interpreted in such a way that the events are placed in a meaningful context and seen as controllable, challenging, and less alienating."

"Resiliency is also studied in the midlife (Bonanno, 2004). Here, again, it is the successful adaptation to traumatic experiences (for instance, a terrorist attack), which is being investigated in the first line. Finally, the term is used with adults meaning the ability to overcome "the stress of life" without developing psychiatric symptoms (Hjemdal, et al., 2006). Common to all these approaches to resilience is "a sense of recovery and rebounding despite adversity and change" (Earvolino-Ramirez, 2007, p. 74)." and "Taking these considerations into account, resilience can be conceptualized as the ability to overcome short-term or chronic stress without deleterious effects of distress. This means that the resilience processes prevent stressors from having negative somatic, behavioral and psychological consequences, which the stressors would have if the resiliency processes were not active. Resilience is inversely related to stress vulnerability. In fact, these are two sides of exactly the same coin."

"Hardiness is an indicator of resiliency and has been identified as a protective factor that reduces the probability of pathogenic psychological reactions (Frederickson, Tugade, Waugh, \& Larkin, 2003; Paton, 1994; Paton, Violanti, \& Smith, 2003). Hardiness is thought to consist of three sets of cognitive styles (Maddi, 1990). Commitment reflects the tendency to find meaning and purpose in potentially stressful events; control refers to the tendency to believe that one is capable of managing the stressful event; and challenge is the tendency to see stressful events as an opportunity for personal growth."

"Psychological capital is defined as "one's positive appraisal of circumstances and probability for success based on motivated effort and perseverance" (Luthans et al. 2007, p. 550)." and "Psychological capital represents an individual's positive psychological state of development that is characterized by four psychological resources: efficacy (confidence to take on and put in the necessary effort to succeed at challenging tasks), hope (one's ability to persevere towards a goal), optimism (a positive expectation about succeeding now and in the future), and resilience (being able to sustain and bounce back to attain success when beset by problems and adversity; Luthans et al. 2007)." and "Thus, based on theory and past research, individuals who score higher in psychological capital can be expected to put forth 
Table 2 (continued)

Author (year, page number)

Definition

extra effort and perseverance based on greater confidence (efficacy), more willpower, and energy to generate multiple solutions to problems or goal blockages (hope); will be more likely to voice positive expectations about results (optimism); and will respond more positively to adversity and setbacks (resilience)."

Yuan et al. (2011, p. 45)

"Resilience has been characterized by the ability to "bounce back from negative emotional experiences and by flexible adaptation to the changing demands of stressful experiences" (Tugade and Fredrickson, 2004). Luthar et al. presented an excellent overview of this construct and suggested using the term "protective factors" when describing processes that alter the effects of adversity (Luthar et al. 2000)." and "(...) the terms "resilience" and "protective factors" have been used interchangeably to describe attributes of trauma survivors which mitigate the development of PTSD symptoms and are associated with the preservation of functioning following traumatic events."

hospitalization and not associated with absenteeism, based on the adjusted $R$-squared of hardiness and controlled for psychological well-being, age, and ethnicity. Cross-sectional studies examined various aspects of physical health. De Terte et al. (2014) found weak to moderate positive associations between resilience and physical health, based on the $R$-squared of resilience and controlled for traumatic event exposure. Velichkovsky (2009) found very weak to moderate negative associations between resilience and chronic illness, smoking, and alcohol use, using correlations and logistic regression analyses. Hills and Norvell (1991) found a very weak positive association between hardiness and physical symptoms, based on the adjusted $R$-squared. Violanti et al. (2014) found with rate ratios a relationship between hardiness commitment and the total score of stressors for 1-day work absences in a binomial regression analysis.

\section{For General Mental Health}

With respect to mental health, cross-sectional studies found a moderate positive association between psychological capital and psychological well-being (Farr-Wharton et al. 2016) and weak to moderate negative associations between psychological capital, anxiety, and depressive symptoms (Ojedokun and Balogun 2015), using SEM analyses. In another SEM analysis, Siu et al. (2015) found a weak negative association between psychological capital and stress symptoms. In contrast, Velichkovsky (2009) found in a correlational analysis a strong negative association between resilience and stress symptoms. Resilience was moderate negatively associated with psychological distress, based on the adjusted $R$-squared of resilience and controlled for traumatic event exposure (de Terte et al. 2014). Andrew et al. (2008) and Andrew et al. (2013) conducted multiple regression analyses and controlled for age, education, and marital status. Based on the standardized regression coefficients, Andrew et al. (2008) and Andrew et al. (2013) found weak to moderate negative associations between hardiness (2008: men: control, women: control and commitment; 2013: men: challenge, control, and commitment, women: control and commitment) and depressive symptoms. Besides that, in men, hardiness was weakly and negatively associated with psychological symptoms (Andrew et al. 2008) and there were weak negative associations between hardiness (men: challenge, control, and commitment; women: commitment) and anxiety symptoms (Andrew et al. 2013).

\section{For PTSD Symptomatology}

In total, eight studies assessed the independent predictive value of resilience for PTSD symptomatology. Longitudinal studies found both no independent effect of hardiness on PTSD symptoms in a multiple regression analysis (Marchand et al. 2015) and very weak independent effects of the resilience facets of "belief in the benevolence of the world" (positive effect) and "social adjustment" (negative effect) on PTSD symptoms, based the adjusted $R$-squared and controlled for ethnicity and traumatic event exposure (Yuan et al. 2011). Cross-sectional studies (Andrew et al. 2008; Andrew et al. 2013; de Terte et al. 2014; Lee et al. 2016; McCanlies et al. 2014; Prati and Pietrantoni 2010) found varying associations between resilience, hardiness, and PTSD symptoms. In linear regression analyses, Andrew et al. (2008) and Andrew et al. (2013) controlled for age, education, and marital status and based on the standardized regression coefficients, they found weak to moderate negative associations between hardiness and PTSD symptoms. Andrew et al. (2008) found that, for women, the hardiness facet commitment was negatively associated with PTSD symptoms. Andrew et al. (2013) found that for men, all hardiness facets were associated with PTSD symptoms; for women, there was an association with the hardiness facets control and commitment. De Terte et al. (2014) found a moderate negative association between resilience and PTSD symptoms, based on the $R$-squared of resilience, while controlling for 
traumatic event exposure. McCanlies et al. (2014) conducted ANCOVAs to examine the relationship between resilience and PTSD symptoms and controlled for age, gender, ethnicity, education, and alcohol use. Based on the standardized regression coefficients, McCanlies et al. (2014) found a strong negative association between resilience and PTSD symptoms. Following Prati and Pietrantoni (2010), resilience was weakly negatively associated with PTSD symptoms, based on the $R$-squared of resilience. In a logistic regression analysis, Lee et al. (2016) found a negative association between resilience and PTSD symptoms, controlling for age, education, marital status, smoking, alcohol use, service area, duration of patrol service, job stress, and depression.

\section{For Burnout}

Four cross-sectional studies examined the relationship between resilience and burnout. Fyhn et al. (2015) found a very weak negative association between hardiness and burnout, based on the adjusted $R$-squared of hardiness and controlled for age, gender, police experience, and position experience. Gupta et al. (2012) found in a correlational analysis a weak to moderate negative association between resilience and burnout, whereas Velichkovsky (2009) found a moderate to strong negative association between resilience and burnout, based on correlations. Hills and Norvell (1991) did not find an association between hardiness and burnout in a stepwise regression analysis.

\section{For Personality}

The two cross-sectional studies on the predictive value of resilience for personality showed in correlational analyses weak to moderate positive associations between resilience and the personality characteristics of conscientiousness and agreeableness (Gupta et al. 2012) and a weak negative association between resilience and type A personality (Velichkovsky 2009).

\section{For Psychological Capital}

Walumbwa et al. (2010) found in a hierarchical linear model that leaders' psychological capital, followers' psychological capital, and service climate were moderately associated with the supervisory-rated performance of followers, based on the $R$-squared. In a cross-sectional design and using SEM analyses, studies found that psychological capital was moderate positively associated with job satisfaction (Siu et al. 2015) and stressors (Farr-Wharton et al. 2016). Hills and Norvell (1991) found a weak negative association between hardiness and job satisfaction in a stepwise regression analysis.

\section{For Interaction and Mediation Effects of Resilience}

Five studies examined the interaction effect of resilience. Tang and Hammontree (1992) found in a longitudinal design a weak interaction effect between hardiness and police stress on absenteeism, based on the adjusted $R$-squared of the interaction effect. In two cross-sectional studies, James et al. (2006) found in a multiple regression analysis no interaction effect between hardiness and dysphoria on anger. Johnsen et al. (2017) found an interaction effect between self-efficacy and hardiness for performance satisfaction, but not for perceived strain, based on an OLS regression analysis.

Lu et al. (2015) and Siu et al. (2015) conducted SEManalyses in cross-sectional designs. Lu et al. (2015) found that job stress and identification with the police organization were very weakly associated with job satisfaction through psychological capital. Siu et al. (2015) found an indirect effect of psychological capital via stress symptoms and job satisfaction to the turnover intention of a police officer.

\section{Discussion}

The first aim of the present systematic review was to assess the predictive values of resilience, hardiness, and psychological capital for (problems in) functioning of police officers. We identified 22 empirical studies, of which the large majority was conducted relatively recently, published between 2013 and 2016 and included police officers working in Western countries. Only five of the identified studies used a longitudinal design.

Results of the studies showed that the identified empirical police studies on resilience, hardiness, and psychological capital were predominantly focused on the predictive value of resilience for physical and mental health variables, such as PTSD symptoms and burnout. Earlier reviews on the general literature about resilience also reported a similar dominance of health-related variables (Almedom and Glandon 2007; Britt et al. 2016). Importantly, the large majority of studies had cross-sectional designs despite the importance and call for longitudinal studies (Britt et al. 2016; Davydov et al. 2010; Luthar et al. 2000) to obtain knowledge about the effect of time on the predictive values of resilience (Britt et al. 2016).

The second aim of the present study was to examine the concepts and measures of resilience, hardiness, and psychological capital are used in studies among police officers. Remarkably, despite the description and definitions of resilience invariably referring to being able to cope successfully with difficult, stressful, or adverse events and thus also leaving space for the assessment of actual behavior of police officers, none of the studies that we identified assessed to what extent police officers who are considered to be resilient actually perform better as a police officer than those who are considered 
not or less resilient. Besides that, no study assessed how resilience actually enables police officers to (keep) carry(ing) out their duties and responsibilities well during their work. In other words, studies on the predictive value of resilience seem to limit resilience in terms of (mental) health implicitly suggesting that as long as officers do not suffer from (mental) health problems, they have the ability to deal with more or less stressful situations effectively in terms of law enforcement. In fact, there is a remarkable group of studies that actually consider resilience as not developing PTSD (Almedom and Glandon 2010; Galatzer-Levy et al. 2011; Galatzer-Levy et al. 2013; Galatzer-Levy et al. 2014; Hennig-Fast et al. 2009; Marmar et al. 2006; Peres et al. 2011; Pietrzak et al. 2014). Within these studies, resilience is defined as a pattern of minimal to none PTSD symptom levels (Galatzer-Levy et al. 2011; Galatzer-Levy et al. 2013; Galatzer-Levy et al. 2014; Pietrzak et al. 2014). The emphasis would seem to be entirely on being healthy "fit for duty" rather than how well that duty is performed under stressful circumstances.

In this review, we see that, despite the fact that resilience and related terms are studied mostly in relation to physical and mental health variables, the associations found were only very weak to moderate. Also, studies that examined the relationship between resilience and non-health variables, such as personality, stress and job performance, found very diverse and weak associations. Again, we have to realize that $80 \%$ of the identified studies were cross-sectional in nature and that these studies used a wide variety of measurements, which makes it complicated to interpret and synthesize any findings. In other words, the described characteristics of the included studies such as the focus on (only) mental health as dependent variable and that studies mostly were conducted in Western countries do introduce bias to some extent.

Resilience and hardiness were studied most frequently in the included studies. We see that the terms hardiness and psychological capital are more uniform in their definitions and concepts than resilience. Resilience is defined in various ways, ranging from single, unidimensional approaches (e.g., Gupta et al. 2012) to heterogeneous, multidimensional approaches (e.g., Britt et al. 2016; de Terte et al. 2014; Prati and Pietrantoni 2010).

Besides that, the included studies used a lot of different measures to investigate resilience, which corresponds well with the conclusions of Windle et al. (2011) and Pangallo et al. (2015). In their methodological reviews, they identified multiple measurement approaches for resilience, although measurements of hardiness and psychological capital varied less than those of resilience. The variety in definitions, conceptualizations, and measurements (Britt et al. 2016; Davydov et al. 2010) may hinder conclusion about potential predictors and outcomes of resilience because it is unclear to which extent different results are caused by, for example, different instruments or study samples.

\section{Limitations}

There are some limitations to this review that have to be mentioned. Concepts that may be related to resilience (for example coping or self-efficacy) were not studied in this literature review: we included studies that focused on resilience according to the text of the published papers. We tried to develop a search strategy that was specific enough to include relevant studies and exclude irrelevant studies. However, it is possible that, despite the search strategies in three big databases, some relevant studies were missed. The majority of included studies were conducted in Western countries. These studies do not give us insight into the predictive value and predictors of resilience among officers in non-Western countries.

Due to limited number of longitudinal studies available, we did not perform a meta-analysis. In addition, we may expect that research in this area is sensitive, like other research areas, to publication bias, e.g., that studies with significant findings are more likely to be published by journals (or submitted to journals) than studies presenting non-significant findings. Thus, although we found little evidence that resilience is a strong and important predictor across studies for especially mental health problems, it is conceivable that, for this reason, our findings still overestimate the predictive value of resilience among police officers (Fanelli 2012; Van Assen et al. 2014; Young et al. 2008). Finally, identified studies had their own limitations and weaknesses. All included studies used self-report data, which can cause potential response biases and less objectivity of findings. The large majority of studies had cross-sectional designs and relatively small sample sizes, which has its limitations in order to draw strong conclusions.

\section{Final Conclusions}

Finally, the risk of implicitly suggesting that resilience, hardiness, and psychological capital are associated only with (mental) health can be demonstrated if we generalize it to other occupations: are healthy teachers good teachers, healthy doctors good doctors, or healthy scientists good scientists? Earlier, Britt et al. (2016, p. 396) discussed this topic in a similar way for the resilience literature in general: "will the same individuals be identified as resilient in the aftermath of adversity when looking at job performance as the criterion versus mental health?". This statement would appear to be true for policing as well, and as such constitutes a major gap in our knowledge on the role of resilience, hardiness, and psychological capital in policing. In either way, this review shows that results of current studies do not provide strong and consistent evidence that resilience, hardiness, and psychological capital are important predictors for the functioning of police officers. Longitudinal studies assessing, besides mental health, the actual performance of police officers are warranted. 
Funding This study is based on a project granted by the Police Academy of the National Police, The Netherlands.

\section{Compliance with Ethical Standards}

Conflict of Interest Authors Kim Janssens, Peter van der Velden, and Marc van Veldhoven declare that they have no conflict of interests. Authors Kim Janssens and Peter van der Velden conducted this study partly at INTERVICT, Tilburg University. Author Ruben Taris is employed at the Police Academy.

Ethical Approval This article does not contain any studies with human participants or animals performed by any of the authors.

Informed Consent Because this study does not contain human participation, informed consent was not necessary to obtain.

Open Access This article is distributed under the terms of the Creative Commons Attribution 4.0 International License (http:// creativecommons.org/licenses/by/4.0/), which permits unrestricted use, distribution, and reproduction in any medium, provided you give appropriate credit to the original author(s) and the source, provide a link to the Creative Commons license, and indicate if changes were made.

\section{References}

Aburn G, Gott M, Hoare K (2016) What is resilience? An integrative review of the empirical literature. J Adv Nurs 72(5):980-1000. https://doi.org/10.1111/jan.12888

Agaibi CE, Wilson JP (2005) Trauma, PTSD, and resilience: a review of the literature. Trauma Violence Abuse 6(3):195-216. https://doi.org/ $10.1177 / 1524838005277438$

Almedom AM, Glandon D (2007) Resilience is not the absence of PTSD any more than health is the absence of disease. J Loss Trauma 12(2): 127-143. https://doi.org/10.1080/15325020600945962

Andersen JP, Dorai M, Papazoglou K, Arnetz BB (2016) Diurnal and reactivity measures of cortisol in response to intensive resilience and tactical training among special forces police. J Occup Environ Med 58(7):e242-e248. https://doi.org/10.1097/JOM. 0000000000000756

Andrew ME, McCanlies E, Burchfiel C, Charles L, Hartley T, Fekedulegn D, Violanti J (2008) Hardiness and psychological distress in a cohort of police officers. Int J Emerg Ment Health 10(2): $137-148$

Andrew ME, Howsare JL, Charles LE, McCanlies EC, Mnatsakanova A, Hartley TA et al (2013) Associations between protective factors and psychological distress vary by gender: the Buffalo Cardio-Metabolic Occupational Police Stress Study. Int J Emerg Ment Health 15(4): 277-288

Atella MD (1999) Case studies in the development of organizational hardiness: from theory to practice. Consult Psychol J Pract Res 51(2):125-134. https://doi.org/10.1037/1061-4087.51.2.125

Avey JB, Reichard RJ, Luthans F, Mhatre KH (2011) Meta-analysis of the impact of positive psychological capital on employee attitudes, behaviors, and performance. Hum Resour Dev Q 22(2):127-152. https://doi.org/10.1002/hrdq.20070

Bartone PT (1995) A short hardiness scale. Retrieved from http://www. hardiness-resilience.com/docs/APS95HAN1.pdf

Bartone PT (2007) Test-retest reliability of the dispositional resilience scale-15, a brief hardiness scale. Psychol Rep 101(3):943-944. https://doi.org/10.2466/pr0.101.3.943-944
Berger W, Coutinho ESF, Figueira I, Marques-Portella C, Luz MP, Neylan TC et al (2012) Rescuers at risk: a systematic review and meta-regression analysis of the worldwide current prevalence and correlates of PTSD in rescue workers. Soc Psychiatry Psychiatr Epidemiol 47(6):1001-1011. https://doi.org/10.1007/s00127-0110408-2

Bonanno GA (2004) Loss, trauma, and human resilience: Have we underestimated the human capacity to thrive after extremely aversive events? Am Psychol 59(1):20

Bowler RM, Harris M, Li J, Gocheva V, Stellman SD, Wilson K, Alper H, Schwarzer R, Cone JE (2012) Longitudinal mental health impact among police responders to the 9/11 terrorist attack. Am J Ind Med 55(4):297-312. https://doi.org/10.1002/ajim.22000

Britt TW, Shen W, Sinclair RR, Grossman MR, Klieger DM (2016) How much do we really know about employee resilience? Ind Organ Psychol 9(2):378-404. https://doi.org/10.1017/iop.2015.107

Brough P, Frame R (2004) Predicting police job satisfaction and turnover intentions: The role of social support and police organisational variables. New Zeal J Psychol 33(1):8-18

Brunetto Y, Teo ST, Shacklock K, Farr-Wharton R (2012) Emotional intelligence, job satisfaction, well-being and engagement: explaining organisational commitment and turnover intentions in policing. Hum Resour Manag J 22(4):428-441

Davydov DM, Stewart R, Ritchie K, Chaudieu I (2010) Resilience and mental health. Clin Psychol Rev 30(5):479-495. https://doi.org/10. 1016/j.cpr.2010.03.003

de Terte I, Stephens C, Huddleston L (2014) The development of a three part model of psychological resilience. Stress Health 30(5):416 424. https://doi.org/10.1002/smi.2625

Earvolino-Ramirez M (ed) (2007) Resilience: A concept analysis. Nurs Forum. Wiley Online Library

Fanelli D (2012) Negative results are disappearing from most disciplines and countries. Scientometrics 90:891-904. https://doi.org/10.1007/ s11192-011-0494-7

Farr-Wharton B, Azzopardi J, Brunetto Y, Farr-Wharton R, Herold N, Shriberg A (2016) Comparing Malta and USA police officers' individual and organizational support on outcomes. Public Money Manag 36(5):333-340. https://doi.org/10.1080/09540962.2016. 1194078

Fletcher D, Sarkar M (2013) Psychological resilience: a review and critique of definitions, concepts, and theory. Eur Psychol 18(1):12-23. https://doi.org/10.1027/1016-9040/a000124

Fox J, Desai MM, Britten K, Lucas G, Luneau R, Rosenthal MS (2012) Mental-health conditions, barriers to care, and productivity loss among officers in an urban police department. Conn Med 76(9):525

Fredrickson BL, Tugade MM, Waugh CE, Larkin GR (2003) What good are positive emotions in crises? A prospective study of resilience and emotions following the terrorist attacks on the United States on September 11th, 2001. J Pers Soc Psychol 84:365-376

Fyhn T, Fjell KK, Johnsen BH (2015) Resilience factors among police investigators: hardiness-commitment a unique contributor. J Police Crim Psychol 31(4):261-269. https://doi.org/10.1007/s11896-0159181-6

Galatzer-Levy IR, Madan A, Neylan TC, Henn-Haase C, Marmar CR (2011) Peritraumatic and trait dissociation differentiate police officers with resilient versus symptomatic trajectories of posttraumatic stress symptoms. J Trauma Stress 24(5):557-565. https://doi.org/10. $1002 /$ jts. 20684

Galatzer-Levy IR, Brown AD, Henn-Haase C, Metzler TJ, Neylan TC, Marmar CR (2013) Positive and negative emotion prospectively predict trajectories of resilience and distress among high-exposure police officers. Emotion 13(3):545-553. https://doi.org/10.1037/ a0031314

Galatzer-Levy IR, Steenkamp MM, Brown AD, Qian M, Inslicht S, Henn-Haase C et al (2014) Cortisol response to an experimental stress paradigm prospectively predicts long-term distress and 
resilience trajectories in response to active police service. J Psychiatr Res 56:36-42. https://doi.org/10.1016/j.jpsychires.2014.04.020

Ganellen RJ, Blaney PH (1984) Hardiness and social support as moderators of the effects of life stress. J Pers Soc Psychol 47(1):156

Garcia-Dia MJ, DiNapoli JM, Garcia-Ona L, Jakubowski R, O'Flaherty D (2013) Concept analysis: resilience. Arch Psychiatr Nurs 27(6):264 270. https://doi.org/10.1016/j.apnu.2013.07.003

Greene RL, Nowack KM (1995) Hassles, hardiness and absenteeism: results of a 3-year longitudinal study. Work Stress 9(4):448-462. https://doi.org/10.1080/02678379508256892

Gupta R, Sood S, Bakhshi A (2012) Relationship between resilience, personality and burnout in police personnel. Int J Manag Sci 1(4):1-5

Hennig-Fast K, Werner NS, Lermer R, Latscha K, Meister F, Reiser M et al (2009) After facing traumatic stress: brain activation, cognition and stress coping in policemen. J Psychiatr Res 43(14):1146-1155. https://doi.org/10.1016/j.jpsychires.2009.03.001

Herrman H, Stewart DE, Diaz-Granados N, Berger EL, Jackson B, Yuen T (2011) What is resilience? Can J Psychiatry 56(5):258-265. https://doi.org/10.1177/070674371105600504

Hills H, Norvell N (1991) An examination of hardiness and neuroticism as potential moderators of stress outcomes. Behav Med 17(1):3138. https://doi.org/10.1080/08964289.1991.9937550

Hjemdal O, Friborg O, Stiles TC, Rosenvinge JH, Martinussen M (2006) Resilience predicting psychiatric symptoms: A prospective study of protective factors and their role in adjustment to stressful life events. Clin Psychol Psychother 13(3):194-201

Honig AL, Sultan S (2006) Reducing trauma through maximizing resiliency: a departmental case study. Traumatology 12(3):217-219. https://doi.org/10.1177/1534765606296270

Hu T, Zhang D, Wang J (2015) A meta-analysis of the trait resilience and mental health. Personal Individ Differ 76:18-27. https://doi.org/10. 1016/j.paid.2014.11.039

Idler EL, Benyamini Y (1997) Self-rated health and mortality: a review of twenty-seven community studies. J Health Soc Behav :21-37

James BJ, Wilson W, McMains MJ (2006) An examination of stress hardiness, dysphoria, and anger among police recruits exposed to stressful police academy training. J Police Crim Psychol 21(2):3754. https://doi.org/10.1007/BF02855683

Johnsen BH, Espevik R, Saus E-R, Sanden S, Olsen OK, Hystad SW (2017) Hardiness as a moderator and motivation for operational duties as mediator: the relation between operational self-efficacy, performance satisfaction, and perceived strain in a simulated police training scenario. J Police Crim Psychol 32:1-9. https://doi.org/10. 1007/s11896-017-9225-1

Johnston MC, Porteous T, Crilly MA, Burton CD, Elliott A, Iversen L et al (2015) Physical disease and resilient outcomes: a systematic review of resilience definitions and study methods. Psychosomatics 56(2):168-180. https://doi.org/10.1016/j.psym.2014.10.005

Kobasa SC (1979) Stressful life events, personality, and health: an inquiry into hardiness. J Pers Soc Psychol 37(1):1-11

Kobasa SC, Maddi SR, Kahn S (1982a) Hardiness and health: a prospective study. J Pers Soc Psychol 42(1):168-177

Kobasa SC, Maddi SR, Puccetti MC (1982b) Personality and exercise as buffers in the stress-illness relationship. J Behav Med 5(4):391-404

Kobasa SC, Puccetti MC (1983) Personality and social resources in stress resistance. J Pers Soc Psychol 45(4):839

Kobasa SC, Maddi SR, Zola MA (1983) Type A and hardiness. J Behav Med 6(1):41-51

Lee J-K, Choi H-G, Kim J-Y, Nam J, Kang H-T, Koh S-B, Oh S-S (2016) Self-resilience as a protective factor against development of posttraumatic stress disorder symptoms in police officers. Ann Occup Environ Med 28(1):58-64. https://doi.org/10.1186/s40557-0160145-9

Leipold B, Greve W (2009) Resilience: A conceptual bridge between coping and development. Eur Psychol 14(1):40-50
Levy-Gigi E, Richter-Levin G, Okon-Singer H, Kéri S, Bonanno GA (2016) The hidden price and possible benefit of repeated traumatic exposure. Stress 19(1):1-7. https://doi.org/10.3109/10253890.2015. 1113523

Lindsay V (2008) Police officers and their alcohol consumption: should we be concerned? Police Q 11(1):74-87. https://doi.org/10.1177/ 1098611107309564

Lu L, Liu L, Sui G, Wang L (2015) The associations of job stress and organizational identification with job satisfaction among Chinese police officers: the mediating role of psychological capital. Int $\mathrm{J}$ Environ Res Public Health 12(12):15088-15099. https://doi.org/ 10.3390/ijerph121214973

Luthans F, Youssef-Morgan CM (2017) Psychological capital: an evidence-based positive approach. Annu Rev Organ Psych Organ Behav 4:339-366. https://doi.org/10.1146/annurev-orgpsych032516-113324

Luthans F, Youssef CM, Avolio BJ (2007) Introduction to psychological capital. In Psychological capital: developing the human competitive edge. Oxford University Press, Oxford

Luthar SS, Cicchetti D, Becker B (2000) The construct of resilience: a critical evaluation and guidelines for future work. Child Dev 71(3): 543-562. https://doi.org/10.1111/1467-8624.00164

Maddi SR, Kobasa SC (1984) The hardy executive: health under stress. J Nutr Educ 18(2):S76-S77. https://doi.org/10.1016/S0022-3182(86) 80108-X

Maddi S (1990) Issues and interventions in stress mastery. U: HS Friedman (Ur.), Personality and disease (str. 121-154). Wiley, New York

Mael F, Ashforth BE (1992) Alumni and their alma mater: A partial test of the reformulated model of organizational identification. J Organ Behav 13:103-123. https://doi.org/10.1002/job.4030130202

Marchand A, Nadeau C, Beaulieu-Prévost D, Boyer R, Martin M (2015) Predictors of posttraumatic stress disorder among police officers: a prospective study. Psychol Trauma Theory Res Pract Policy 7(3): 212-221. https://doi.org/10.1037/a0038780

Marmar CR, McCaslin SE, Metzler TJ, Best S, Weiss DS, Fagan J et al (2006) Predictors of posttraumatic stress in police and other first responders. Ann N Y Acad Sci 1071(1):1-18. https://doi.org/10. 1196/annals.1364.001

McCanlies EC, Mnatsakanova A, Andrew ME, Burchfiel CM, Violanti JM (2014) Positive psychological factors are associated with lower PTSD symptoms among police officers: post hurricane Katrina. Stress Health 30(5):405-415. https://doi.org/10.1002/smi.2615

McCreary DR, Thompson MM (2006) Development of two reliable and valid measures of stressors in policing: The operational and organizational police stress questionnaires. Int J Stress Manage 13(4):494

Moher D, Liberati A, Tetzlaff J, Altman DG (2009) Preferred reporting items for systematic reviews and meta-analyses: the PRISMA statement. Ann Intern Med 151(4):264-269

Ojedokun O, Balogun SK (2015) The costs of policing: psychosocial capital and mental health outcomes in a Nigeria police sample. Span J Psychol 18(E78):1-10. https://doi.org/10.1017/sip.2015.76

Olsson CA, Bond L, Burns JM, Vella-Brodrick DA, Sawyer SM (2003) Adolescent resilience: a concept analysis. J Adolesc 26(1):1-11. https://doi.org/10.1016/S0140-1971(02)00118-5

Pangallo A, Zibarras L, Lewis R, Flaxman P (2015) Resilience through the lens of interactionism: a systematic review. Psychol Assess 27(1):1-20. https://doi.org/10.1037/pas0000024

Paton D (1994) Disaster relief work: an assessment of training effectiveness. J Trauma Stress 7:275-288

Paton D, Violanti JM, Smith LM (2003) Promoting capabilities to manage posttraumatic stress: Perspectives on resilience. Charles C. Thomas, Springfield, Ill

Paton D, Violanti JM, Johnston P, Burke KJ, Clarke J, Keenan D (2008) Stress shield: a model of police resiliency. Int J Emerg Ment Health 10(2):95-107 
Peres JF, Foerster B, Santana LG, Fereira MD, Nasello AG, Savoia M et al (2011) Police officers under attack: resilience implications of an fMRI study. J Psychiatr Res 45(6):727-734. https://doi.org/10.1016/ j.jpsychires.2010.11.004

Pierce M, Molloy G (1990) Psychological and biographical differences between secondary school teachers experiencing high and low levels of burnout. Br J Educ Psychol 60:37-51

Pietrzak R, Feder A, Singh R, Schechter C, Bromet EJ, Katz C et al (2014) Trajectories of PTSD risk and resilience in world trade center responders: an 8-year prospective cohort study. Psychol Med 44(01):205-219. https://doi.org/10.1017/S0033291713000597

Prati G, Pietrantoni L (2010) Risk and resilience factors among Italian municipal police officers exposed to critical incidents. J Police Crim Psychol 25(1):27-33. https://doi.org/10.1007/s11896-009-9052-0

Ramey SL, Perkhounkova Y, Hein M, Chung S, Franke WD, Anderson AA (2016) Building resilience in an urban police department. J Occup Environ Med 58(8):796-804. https://doi.org/10.1097/JOM. 0000000000000791

Rutter M (1985) Resilience in the face of adversity: Protective factors and resistance to psychiatry disorder. Br J Psychiatry, 147:598-611

Schneider B, White SS, Paul MC (1998) Linking service climate and customer perceptions of service quality: Test of a causal model. J Appl Psychol 83:150-163

Shochet IM, Shakespeare-Finch J, Craig C, Roos C, Wurfl A, Hoge R, Young RMD, Brough P (2011) The development and implementation of the promoting resilient officers (PRO) program. Traumatology 17(4):43-51. https://doi.org/10.1177/ 1534765611429080

Siu O-1, Chow S, Phillips DR, Lin L (2006) An exploratory study of resilience among Hong Kong employees: Ways to happiness. Hapiness Policy :209-20

Siu OL, Cheung F, Lui S (2015) Linking positive emotions to work wellbeing and turnover intention among Hong Kong police officers: the role of psychological capital. J Happiness Stud 16(2):367-380. https://doi.org/10.1007/s10902-014-9513-8

Slaven JE, Mnatsakanova A, Burchfiel CM, Smith LM, Charles LE et al (2011) Association of sleep quality with depression in police officers. Int J Emerg Ment Health 13(4):267-277

Stanley IH, Hom MA, Joiner TE (2016) A systematic review of suicidal thoughts and behaviors among police officers, firefighters, EMTs, and paramedics. Clin Psychol Rev 44:25-44. https://doi.org/10. 1016/j.cpr.2015.12.002

Taloyan M, Kecklund G, Thörn L, Kjeldgård L, Westerlund H, Svedberg P, Alexanderson K (2016) Sickness presence in the Swedish police in 2007 and in 2010: associations with demographic factors, job characteristics, and health. Work 54(2):379-387. https://doi.org/10. 3233/WOR-162333

Tang TL-P, Hammontree ML (1992) The effects of hardiness, police stress, and life stress on police officers' illness and absenteeism. Public Pers Manag 21(4):493-510. https://doi.org/10.1177/ 009102609202100406
Tugade MM, Fredrickson BL (2004) Resilient individuals use positive emotions to bounce back from negative emotional experiences. J Pers Soc Psychol 86(2):320

Tusaie K, Dyer J (2004) Resilience: A historical review of the construct. Holist Nurs Pract 18(1):3-10

Van Assen MALM, Van Aert RCM, Nuijten MB, Wicherts JM (2014) Why publishing everything is more effective than selective publishing of statistically significant results. PLoS One 9(1):e84896. https:// doi.org/10.1371/journal.pone.0084896

van der Velden PG, Kleber RJ, Grievink L, Yzermans CJ (2010) Confrontations with aggression and mental health problems in police officers: the role of organizational stressors, life-events and previous mental health problems. Psychol Trauma Theory Res Pract Policy 2:135-144

Velichkovsky BB (2009) Primary and secondary appraisals in measuring resilience to stress. Psychol Russ 2(1):539-563. https://doi.org/10. 11621/pir.2009.0027

Violanti JM, Fekedulegn D, Hartley TA, Andrew ME, Charles L, TinneyZara CA, Burchfiel CM (2014) Police work absence: an analysis of stress and resiliency. J Law Enforcement Leadersh Ethics 1(1):49

Wagnild GM, Young HM (1993) Development and psychometric evaluation of the Resilience Scale. J Nurs Meas

Walumbwa FO, Avolio BJ, Zhu W (2008) How transformational leadership weaves its influence on individual job performance: The role of identification and efficacy beliefs. Pers Psychol 61:793-825

Walumbwa FO, Peterson SJ, Avolio BJ, Hartnell CA (2010) An investigation of the relationships among leader and follower psychological capital, service climate, and job performance. Pers Psychol 63(4): 937-963. https://doi.org/10.1111/j.1744-6570.2010.01193.x

Wiebe DJ, McCallum DM (1986) Health practices and hardiness as mediators in the stress-illness relationship. Health Psychol 5(5):425

Windle G (2011) What is resilience? A review and concept analysis. Rev Clin Gerontol 21(2):152-169. https://doi.org/10.1017/ S0959259810000420

Windle G, Bennett KM, Noyes J (2011) A methodological review of resilience measurement scales. Health Qual Life Outcomes 9(1):8. https://doi.org/10.1186/1477-7525-9-8

Wu G, Feder A, Cohen H, Kim JJ, Calderon S, Charney DS et al (2013) Understanding resilience. Front Behav Neurosci 7:10

Young NS, Ioannidis JPA, Al-Ubaydli O (2008) Why current publication practices may distort science. PLoS Med 5(10):e201. https://doi.org/ 10.1371/journal.pmed.0050201

Youssef CM, Luthans F (2007) Positive organizational behavior in the workplace: The impact of hope, optimism, and resilience. J Manage 33(5):774-800

Yuan C, Wang Z, Inslicht SS, McCaslin SE, Metzler TJ, Henn-Haase C et al (2011) Protective factors for posttraumatic stress disorder symptoms in a prospective study of police officers. Psychiatry Res 188(1):45-50. https://doi.org/10.1016/j.psychres.2010.10.034 